\title{
Role of Helmet Fit on Angular and Linear Accelerations of Head in Ice Hockey
}

\author{
Hesam Sarvghad Moghaddam ${ }^{1, ~ *, ~ W h i t m a n ~ K w o k ~}{ }^{2}$ \\ ${ }^{1}$ Mechanical Engineering Department, Northern Arizona University, Flagstaff, USA \\ ${ }^{2}$ ZAM Worx, Foster City, USA
}

Email address:

hesam.moghaddam@nau.edu (H. S. Moghaddam)

${ }^{*}$ Corresponding author

\section{To cite this article:}

Hesam Sarvghad Moghaddam, Whitman Kwok. Role of Helmet Fit on Angular and Linear Accelerations of Head in Ice Hockey. International Journal of Biomedical Science and Engineering. Vol. 7, No. 2, 2019, pp. 26-32. doi: 10.11648/j.ijbse.20190702.11

Received: August 6, 2019; Accepted: August 23, 2019; Published: September 6, 2019

\begin{abstract}
Increasing the protection efficiency of helmets is counted as the biggest challenge in ice hockey. The main objective of this study is twofold: first to understand the effect of fitting on the protection capability of ice hockey helmets, and second to determine a possible optimal fit with respect to minimum head accelerations. A purpose-built monorail drop tower was utilized to perform front and front boss impacts at a velocity of $4.47 \mathrm{~m} / \mathrm{s}$ on a custom headform outfitted with a commercial helmet (CCM Resistance) with no gap (tight fit), $2 \mathrm{~mm}$ (regular fit), and $5 \mathrm{~mm}$ gaps (loose fit). It was observed that while in both impacts linear accelerations were lower for the regular fit model, the loose fit model predicted the lowest angular accelerations. A loosely-fitted helmet provides non-deterministic shifting upon impact which generally leads to a wider standard deviation of linear and angular accelerations. The results indicated that in front impacts while introducing a gap reduced the risk of focal injuries, only the loose fit model suggested lower risks of concussive injuries. However, the regular and loose fit models showed better protection against focal and concussive injuries in the front boss impacts, respectively.
\end{abstract}

Keywords: Ice Hockey, Helmet, Fitting, Concussion, Head Acceleration

\section{Introduction}

Mild traumatic brain injuries (mTBI), have become an inevitable outcome of many contact sports such as ice hockey which has one of highest incidence rates of brain trauma [1-4]. About 1.8 to 3.6 million cases of mTBI have been reported for sport and recreational activities with $65 \%$ of them occurring among youth athletes (5 to 18 years old) $[5,6]$. Prevalence of concussive injuries and the lifetime neurodegenerative disorders associated with them have risen many concerns in the past decades which has been the motivation of much research [7-11]. Moreover, besides concussive injuries, many sub-concussive impacts have been recorded during the course of given games or collegiate seasons $[12,13]$. While the severity of these impacts is lower than the concussion level, accumulation of such impacts can cause long-term brain dysfunctions [14-16]. The high incidence rate and life-threatening consequences of head injuries have led to the development of strict safety standards and mandated use of helmets. Underlying injury mechanisms as well as the safety metrics associated with the helmet design are the two major factors that can determine the extent to which helmets protect the head against impacts [17-19]. Head kinematics in terms of linear and angular accelerations is responsible for different injury mechanisms and hence many thresholds have been developed based on these parameters [9, 20-23]. While focal injuries have been shown to be derived mainly by linear accelerations, diffuse injuries have been associated with angular accelerations [14, 17, 20, 24-26].

The advent and evolution of Ice hockey helmets have significantly contributed to the mitigation of focal injuries such as subdural hematoma and skull fracture [1, 17, 27, 28]. However, incidence of diffuse injuries such as concussion and diffuse axonal injuries (DAI) are still common [29-33]. This is in part because the current helmet's safety metrics consider measures such as absorption of impact energy, retention, and penetration resistance performance which mainly affects the peak linear acceleration. Hence, the majority of the studies has focused on the development of new shell designs and liner 
materials for helmets [34-37]. However, sizing of helmets is one of major issues that has not been addressed in most studies. Reviewing ASTM and CSA standards and associated metrics for different sport helmets, Hasltead et al. [38] mentioned that the safety standards of hockey helmets can be improved without compromising the cost or marketability attributes of these helmets.

Currently, a given helmet model is typically manufactured in only a few sizes which crudely approximates the different head sizes and shapes among athletes. This will lead to fitting [39] issues that can greatly impact the protection efficacy of hockey helmets [40-45]. Upon wearing the helmet, a variable spacing is developed between the player's head and the liner. This spacing and the subsequent fit influences the protection capability of the helmet against head injuries [43, 44]. While Hopes and Chinn [44] did not observe any significant difference in the energy absorption of the helmet, Gilchrist and Mills [45] reported that the helmet fit greatly affected the performance of the helmet. Chang et al. [41] used a finite element model to evaluate the effect of fit on the efficiency of motorcycle helmets in mitigating the head injuries. They changed the fitness of the helmet through (1) scaling the headform and (2) scaling the helmet and found a remarkable improvement in protection in the case the headform was scaled. It is safe to assert that the majority of researchers studying sports-related head injuries employ Hybrid III and NOCSAE headforms to conduct their experiments and investigate the kinematic responses of the helmeted heads [14, 20, 29, 46-49]. While these headforms provide invaluable information on the injury risk, they fail to include all the different configurations in the real world due to the mismatch between the head shapes and helmets. Few studies have looked into effects of the proper helmet fit on the cervical spine movement prone to log roll or after securing the athlete to the spine board. [50-53]. Using commercial headforms and helmets, these studies found out that the proper fit only increased the transverse motion of the head. Greenhill et al. [43] observed elevated concussion risk with poorly fitted helmets in their study on a cohort of 4580 high-school football players through evaluating 13 different concussive symptoms such as hyperexcitability, drowsiness, and amnesia. Several other studies have also reported the head injury risks associated with poorly fitted helmets [40-42]

While many studies have investigated the protective potential of helmets against head injuries, they have overlooked the issue of helmet fit [54-57]. This suggest that improper helmet fitting is counted as a major risk factor in sport-related head injuries and should be minimized through introduction of new safety standards and testing methods. To the authors' best knowledge, no study has focused on the effect of helmet fit on the mitigation of brain injury risk in ice hockey. Accordingly, the main objective of this study is twofold: first to understand the effect of fitting on the protection capability of hockey helmets, and second to determine a possible optimal fit with respect to minimum head accelerations.

\section{Methods}

\subsection{Experimental Testing}

Three adult male 50th percentile custom headforms were attached to a flexible neck form (both manufactured out of acrylonitrile butadiene styrene (ABS)) and were used for the experimental tests. The neck form mimicked the range of motions of the cervical spine and the approximate resistance based on the study [39]. The baseline headform was developed using a 3D scan of the interior of the CCM Resistance helmet. The CCM Resistance helmet used for this study is certified by the Canadian Standards Association's Z262.109 and Hockey Equipment Certification Council ASTM F1045-07 and is representative of the ice hockey helmets commercially available. The baseline headform ensured a consistent fit as defined by a constant pressure (or gap) between the helmet and the headform [58]. To this end, a series of force sensors were used to validate constant compressive pressure against the headform. The headform was adjusted accordingly and reprinted to achieve a perfect fit between the headform and the helmet, and is referred to as the "tight fit" model from now on. The other two headforms were adjusted off this baseline case, with the second headform being $2 \mathrm{~mm}$ smaller in all dimensions, and the third headform $5 \mathrm{~mm}$ smaller in all dimensions, referred to as "regular fit" and "loose fit" models, respectively.

Each of the three helmeted headforms were impacted at a velocity of $4.47 \mathrm{~m} / \mathrm{s}$ on the helmet in two locations, five times per location for a total of 30 impacts. Figure 1 shows different impact locations for the helmeted heads from different views. The first impact location, front, was to the anterior intersection of the mid-sagittal and transverse planes. The second impact, front boss, occurred at the midpoint between the anterior mid-sagittal and right coronal planes in the transverse plane with an impact angle of 45 degrees in the transverse plane (Figure 1).

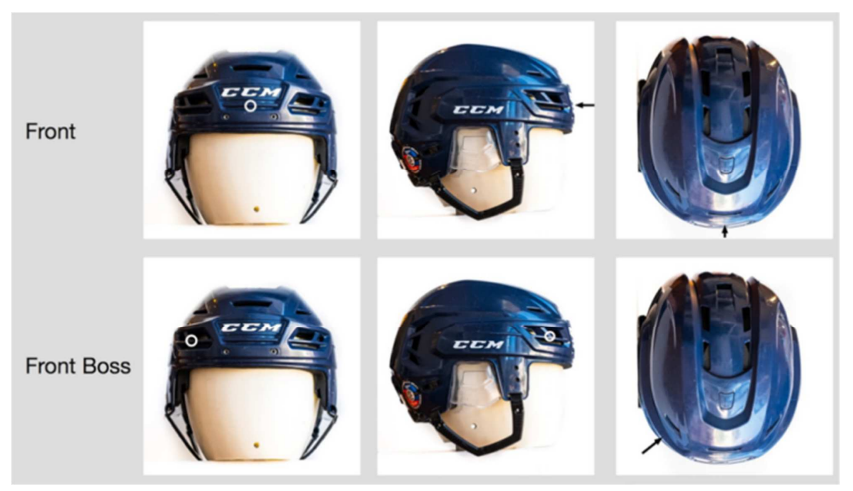

Figure 1. Impact locations on the helmeted headform from different views.

\subsection{Equipment}

Figure 2 shows the purpose-built drop assembly consisting of a monorail guidance system, drop carriage, custom headforms and a data collection system that was used to 
provide three-dimensional impacts for three distinct headforms using a single commercially available ice hockey helmet. Except where noted, the testing procedures followed the specifications of Standard Performance Specification for Ice Hockey Helmets F1045-15. It should be noted that the nature of the experiments required dimensional changes to the headform. The monorail guidance system consisted of a 2525 $\mathrm{mm}$ precision rail system capable of drop velocities greater than $7 \mathrm{~m} / \mathrm{s}$. The impact surface consisted of a 60 shore A modular elastomer programmer (MEP) anvil. For better visualization of the impact as well as annotation of coordinate system and head direction, a close-up of the helmeted head impact with the anvil is shown on the right side of Figure 2. A set of laser gates were used at about $1 \mathrm{~cm}$ above the MEP anvil to confirm the impact velocity prior to contact with the MEP covered anvil. The monorail has a pneumatically driven lift and adjustable height presets. For our impact, the height was set at $1.05 \mathrm{~m}$ to achieve the corresponding $4.47 \mathrm{~m} / \mathrm{s}$ test velocities. This test velocity was selected to match the CSA and HECC standards and replicate fall events in ice hockey [59] The carriage system slid along the monorail and allowed the attachment of any number of custom headforms. The headforms weighed $2.91 \mathrm{~kg}, 2.97 \mathrm{~kg}$ and $3.00 \mathrm{~kg}$ from the smallest to the largest headform. The combined weight of the carriage, head and neck assembly is $4.0 \mathrm{~kg}$ with only. $55 \mathrm{~kg}$ of the weight on the carriage assembly itself or within the same specification as $535 \mathrm{~mm}$ headform used in ASTM testing. The data acquisition consisted of a 3-axis ADXL377 accelerometer and a ITG-3200 gyro, both sampling at $3.5 \mathrm{kHz}$. An additional single access ADXL001 accelerometer was used to measure linear accelerations in the range of 200 to $500 \mathrm{~g}$, though the measurements did not reach this level for this paper. The sensors were placed in the center of the headforms to capture both the linear and angular accelerations experienced by the headform.

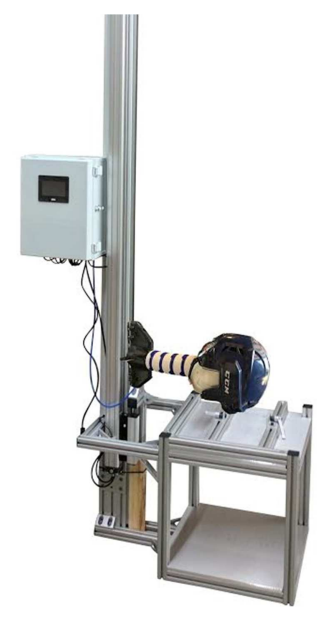

Figure 2. Monorail drop rail used to simulate fall impacts in ice hockey (left) and closer view of head/neck and helmet assembly at the time of impact on anvil (right).

\section{Results}

The performance of the CCM Resistance hockey helmet with respect to fitting quality was evaluated over six impact conditions across two impact locations and three differently sized headforms. Impact results in terms of peak linear and angular accelerations are presented in Table 1 . The values for the linear acceleration ranged from $62 \mathrm{~g}$ (regular fit, front boss impact) to $89.2 \mathrm{~g}$ (loose fit, front boss impact). The values for the angular acceleration ranged from $3209 \mathrm{rad} / \mathrm{s}^{2}$ (loose fit, front boss impact) to $4629 \mathrm{rad} / \mathrm{s}^{2}$ (regular fit, front impact). The results for the front boss impacts on the regular fit model were the most interesting when contrasted with those for the frontal impact. Introducing a $2 \mathrm{~mm}$ gap (regular fit) to our baseline model resulted in $11 \%$ and $30 \%$ reduction in linear acceleration in the front and front boss impacts, respectively. Figures 3 and 4 show graphical comparisons of peak linear and angular accelerations among different fitting models, respectively.

\subsection{Acceleration Results in Front Impact}

For the front impacts, the tight fit and regular fit models predicted the highest linear and angular accelerations at $84.1 \mathrm{~g}$ $(\mathrm{p}<0.05)$ and $4629 \mathrm{rad} / \mathrm{s}^{2}$, respectively. The loose fit model, on the other hand, resulted in both the lowest linear (74.1g) $(\mathrm{p}<0.05)$ and angular $\left(3610 \mathrm{rad} / \mathrm{s}^{2}\right)$ accelerations. For the front impacts on the tight fit model, we also observed that the helmet was snugly fit on the headform and didn't move more than several millimeters from its original position on the headform. In contrast, both the regular fit and loose fit models moved significantly upon impact with the MEP anvil. While introducing a $2 \mathrm{~mm}$ gap (regular fit) to our baseline model resulted in $11 \%$ reduction in linear acceleration, it increased the angular acceleration by $19 \%$.

\subsection{Acceleration Results in Front Boss Impact}

For the front boss impacts, the loose fit and tight fit models predicted the highest linear and angular accelerations at $89.2 \mathrm{~g}$ $(\mathrm{p}<0.05)$ and $4495 \mathrm{rad} / \mathrm{s}^{2}$, respectively. Figure 3 shows the comparisons of linear accelerations while Figure 4 shows the comparison for angular accelerations. Moreover, the lowest linear and angular accelerations were observed for the regular fit $(62 \mathrm{~g})(\mathrm{p}<0.05)$ (Figure 3) and loose fit $\left(3209 \mathrm{rad} / \mathrm{s}^{2}\right)$ (Figure 4) models, respectively. The regular fit model provided significant improvements by reducing the linear and angular accelerations by $26.6 \mathrm{~g}(\mathrm{p}<0.05)$ and almost $500 \mathrm{rad} / \mathrm{s}^{2}$, respectively, over the tight fit model. Similar to the frontal impact, our observations suggested that significant movements of the helmet on the headform acted to deflect and absorb both linear and angular forces. The loose fit model, however, showed a significant rise in linear accelerations over the regular fit model. 
Table 1. Peak acceleration results for different helmet fitting and impact locations. Standard deviation in parentheses.

\begin{tabular}{llll}
\hline \multirow{2}{*}{ Impact Direction } & Fitting Model (gap) & Peak Accelerations (SD) & Angular (rad/s $)$ \\
\cline { 3 - 4 } & Tight Fit $(0)$ & $84.1(2.5)$ & $3889(1003)$ \\
\multirow{3}{*}{ Front } & Regular Fit $(2 \mathrm{~mm})$ & $74.9(3.2)$ & $4629(1361)$ \\
& Loose Fit $(5 \mathrm{~mm})$ & $74.1(2.0)$ & $3610(330)$ \\
\multirow{2}{*}{ Front Boss } & Tight Fit $(0)$ & $88.6(1.9)$ & $4495(548)$ \\
& Regular Fit $(2 \mathrm{~mm})$ & $62.0(4.3)$ & $3988(1090)$ \\
\hline
\end{tabular}

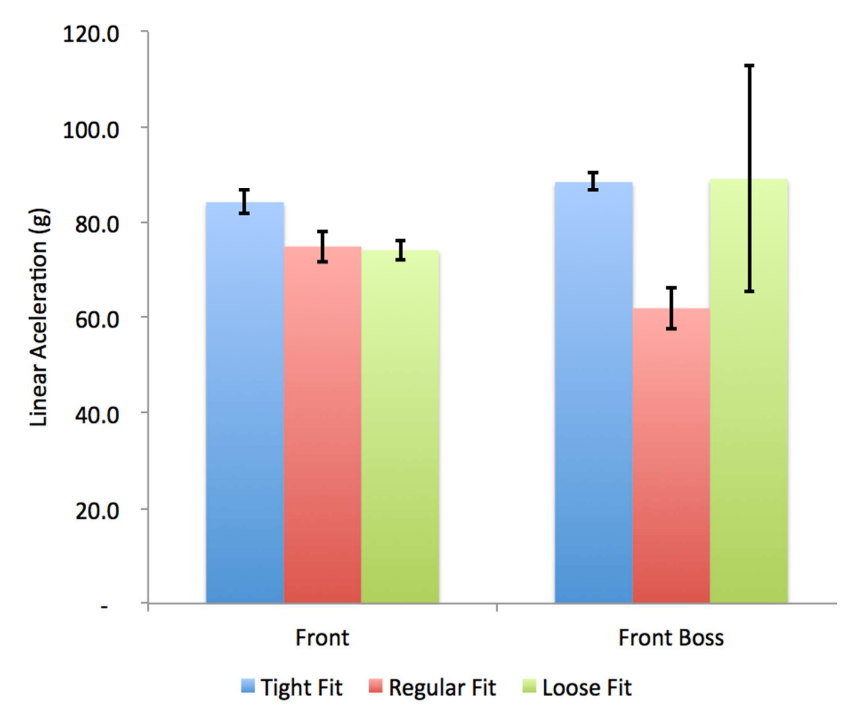

Figure 3. Linear acceleration comparison for the impacts across different fitting head forms.

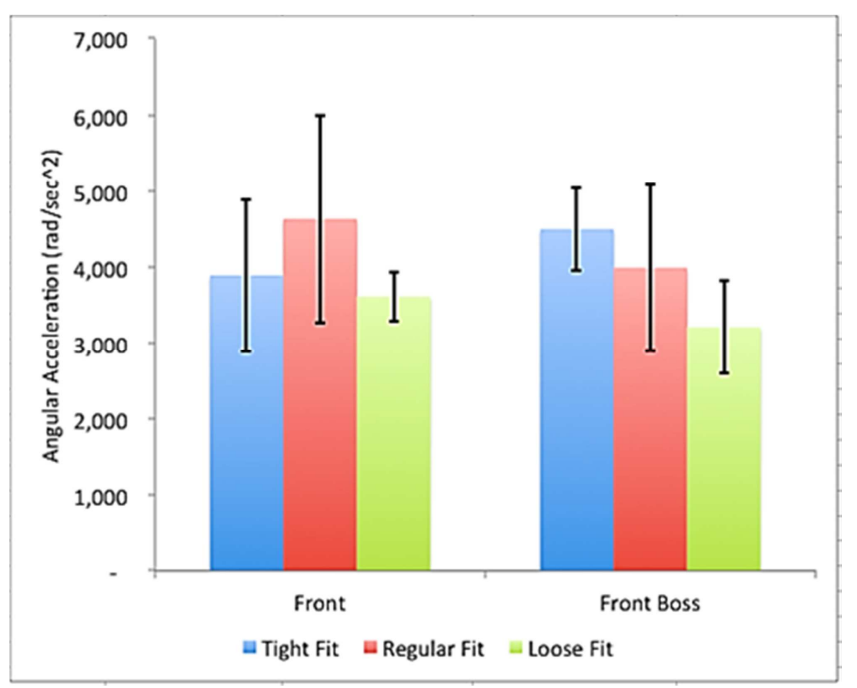

Figure 4. Angular acceleration comparison for the impacts across different fitting head forms.

\section{Discussion}

The effect of fitting on the linear and angular accelerations of helmeted heads for concussive impacts during fall events in ice hockey was carried out with respect to the impact location. Fall on ice has been introduced as the major cause of brain injury in ice hockey, due to the shorter duration of fall events as well as high energy transfer to the head $[30,60]$. To this end, impacts were performed at a velocity of $4.7 \mathrm{~m} / \mathrm{s}$ representative of fall events. Figure 2 shows the moment that the helmeted headform impacts the anvil at this velocity. The quality of helmet fitting resulted in significant differences between acceleration responses for the impacts on the helmeted headforms. The magnitudes of linear accelerations all suggested $25 \%$ to more than $50 \%$ ( $>88 \mathrm{~g}$ ) risk of mild traumatic brain injuries (mTBI) [20, 61-63], with the front boss impact predicting the highest injury risk in the loose fit model. However, all angular acceleration data identified less than $50 \%$ risk of concussive injuries, with the loose fit model showing no injury risk for both front and front boss impacts. The regular fit predicted the highest peak angular acceleration in the front impact. A noticeable decrease in the peak linear acceleration was observed in the front impact as the gap was increased to $2 \mathrm{~mm}$ (regular fit) This was found to be due to the fact that the loosely-fitted helmet was able to move more freely against the smaller headform (as determined by the helmet position after the impact), resulting in partial impact deflection and energy absorption. However, the regular fit and loose fit models predicted statistically similar linear accelerations responses due to the alignment of frontal impacts along the center of mass of the head in the sagittal plane and the axis of the neck. This results in the occipital portion of the helmet and chin strap preventing the helmet from rotating from the top to the back of the head beyond a given range of rotation such that both models had comparable motions. This suggested while different fitting model were able to maintain the linear acceleration at about $74 \mathrm{~g}$ (about $35 \%$ mTBI risk), as shown in Figure 3, greater gaps could significantly decrease the angular accelerations (3610 $\left.\mathrm{rad} / \mathrm{s}^{2}\right)$ to well below the injury risk levels. This is in accordance with the observations of $[14,64]$. The future use of headforms with regular markings on the back would allow a more precise measurement of the helmet movement and validate that their movement is limited to a finite maximum.

Both linear and angular accelerations were observed to be quite sensitive to the impact location. This coincides with many studies which have investigated the effect of impact location on the acceleration responses of helmeted headforms $[12,22,65]$. Also, computational works have shown the effect of impact direction on the dynamics responses of the brain tissue [49, 66, 67]. This is of great importance since it can greatly contribute to the design of improved helmets with increased protection capability. Accordingly, different patterns in both linear and angular accelerations were 
observed for the front boss impacts. While a consistent decline was observed in the angular accelerations, the linear accelerations had a significant rise by increasing the gap to $5 \mathrm{~mm}$. It was because that in the case of front boss impacts, higher torsional forces caused the twisting of the helmet and consequently contact of the headform with the anvil (i.e. the helmet partially or fully dismounting the head form) which resulted in the linear accelerations to exceed $88 \mathrm{~g}$ introducing more than $50 \%$ risk of mTBI. However, in the regular fit model where the helmet was able to stay affixed, significant rotation of the helmet deflected both linear and angular accelerations to below $65 \mathrm{~g}$ and $4000 \mathrm{rad} / \mathrm{s}^{2}$, respectively. The consistent decline of the angular acceleration with increasing the gap size occurred as a result of the free rotation of the helmet about the headform which agrees with the results of [41] which was carried out for the effect of fit in motorcycle helmets.

Based on our data, the loose fit model with a $5 \mathrm{~mm}$ gap provided increased protection levels specifically against concussive and diffuse injuries which are mainly associated with head rotation $[24,57,68]$ by significantly reducing the angular accelerations in both impacts, as shown in Figure 4. Moreover, it showed improved performance for the helmet as it reduced the linear acceleration to the same level as the regular fit in the front impact but failed to manage the linear acceleration in the front boss impacts. This could introduce potential limitations in developing an optimal fit capable of reducing the linear and angular accelerations to the same degree. One possible resolution could be improving of the shell and liner material, as well as the design of the helmet. The effect of helmet design and shell/liner materials have been studied by several researchers $[14,17,37,62]$ which reported use of 3D structures to manage linear acceleration, as well as use of thicker liners and bigger helmets shells to improve the protection efficiency of sports helmets by comparing different types of helmets.

This research is best represented when studied by considering its limitations. While the custom headform /neck used for this study follow the standards of impact research, they were not directly compared to the Hybrid III equivalents or human cadavers to replicate the exact kinematic responses produced by the human head/neck. The impact scenario considered in our study was representative of fall events in ice hockey which serves as the main cause of injury. Inclusion of velocities corresponding to other major events such as collision and puck impacts, as well as more impact locations are necessary for future improvements.

\section{Conclusions}

Improper fit of ice hockey helmets can result in elevated risks of concussion and TBI. Even with the limited number of helmet sizes in hockey, the selection or adjustment of the helmet fit may yield material benefits to the wearer. This study set off to investigate the effect of helmet fitting on the risk of brain injury among hockey players considering different locations. Our results showed that while introducing different levels of fitting could reduce the acceleration responses in helmeted impact, they sometimes may cause adverse effects due to the extreme rotation or detachment of helmet from the head. Impact location was observed to significantly affect the protection capability of the helmet, suggesting the need for development of safer helmets. The looser-fitted helmets showed the management of kinematic responses for front boss impacts, especially in terms of the angular accelerations. Our data showed that each fitting models, even with only a few millimeters in difference, can manage linear and angular accelerations to different extents, which reiterated the need for combining linear and angular accelerations in the study of brain injury. The large variation of acceleration data with the fitting levels and the impact location in helmeted impacts, suggest the need for an optimal fit which can provide maximum protection regardless of the direction of impact. This may require the helmet manufacturers to produce helmets in more sizes, improvements in existing fitting mechanisms and develop advanced tools for measuring the fitting quality.

\section{Recommendations}

Based on the results of this study, the authors would like to recommend the following to reduce the risks of traumatic brain injury:

1. Sports helmets such as ice hockey helmets should be custom made for players based on their headform to provide the best fitting.

2. 3D structures can be used to manage linear acceleration, and thicker liners and bigger helmets shells can improve the protection efficiency of sports helmets.

3. Since the impact location highly affects the level of head kinematics as well as the dynamic responses of the brain, modular design of the helmets is necessary.

\section{References}

[1] Wennberg, R. and Tator, C. National Hockey League reported concussions, 1986-87 to 2001-02. Canadian Journal of Neurological Sciences/Journal Canadien des Sciences Neurologiques, 2003. 30 (03): p. 206-209.

[2] LaPrade, R., Wijdicks, C., and Spiridonov, S. A prospective study of injuries in NCAA intercollegiate ice-hockey goaltenders. Proceedings of Fifth International Symposium on Safety in Ice Hockey, 2009.

[3] Hutchison, M. G., Comper, P., Meeuwisse, W. H., and Echemendia, R. J. A systematic video analysis of National Hockey League (NHL) concussions, part I: who, when, where and what? British journal of sports medicine, 2013: p. bjsports-2013-092234.

[4] Wilcox, B. J., Beckwith, J. G., et al. Biomechanics of head impacts associated with diagnosed concussion in female collegiate ice hockey players. Journal of biomechanics, 2015. 48 (10): p. 2201-2204.

[5] Daneshvar, D. H., Nowinski, C. J., McKee, A. C., and Cantu, R. C. The epidemiology of sport-related concussion. Clinics in sports medicine, 2011. 30 (1): p. 1-17. 
[6] Kontos, A. P., Elbin, R. J., et al. Incidence of Concussion in Youth Ice Hockey Players. Pediatrics, 2016.

[7] Langlois, J. A., Rutland-Brown, W., and Wald, M. M. The epidemiology and impact of traumatic brain injury: a brief overview. The Journal of head trauma rehabilitation, 2006. 21 (5): p. 375-378.

[8] Omalu, B I., DeKosky, S. T., et al. Chronic traumatic encephalopathy in a National Football League player. Neurosurgery, 2005. 57 (1): p. 128-134.

[9] Rowson, S. and Duma, S. M. Brain injury prediction: assessing the combined probability of concussion using linear and rotational head acceleration. Annals of biomedical engineering, 2013. 41 (5): p. 873-882.

[10] McCrory, P., Meeuwisse, W., et al. Consensus statement on concussion in sport: the 3rd International Conference on Concussion in Sport held in Zurich, November 2008. Journal of athletic training, 2009. 44 (4): p. 434-448.

[11] Marshall, S., Bayley, M., McCullagh, S., Velikonja, D., and Berrigan, L. Clinical practice guidelines for mild traumatic brain injury and persistent symptoms. Canadian Family Physician, 2012. 58 (3): p. 257-267.

[12] Schnebel, B., Gwin, J. T., Anderson, S., and Gatlin, R. In vivo study of head impacts in football: a comparison of National Collegiate Athletic Association Division I versus high school impacts. Neurosurgery, 2007. 60 (3): p. 490-496.

[13] Guskiewicz, K. M. and Mihalik, J. P. Biomechanics of sport concussion: quest for the elusive injury threshold. Exercise and sport sciences reviews, 2011. 39 (1): p. 4-11.

[14] Oeur, R. A., Zanetti, K., and Hoshizaki, T. B. Angular acceleration responses of American football, lacrosse and ice hockey helmets subject to low-energy impacts. Proceedings of Proceedings of the IRCOBI Conference, 2014.

[15] McKee, A. C., Stein, T. D., et al. The spectrum of disease in chronic traumatic encephalopathy. Brain, 2013. 136 (1): p. 43-64.

[16] Bailes, J. E., Petraglia, A. L., Omalu, B. I., Nauman, E., and Talavage, T. Role of subconcussion in repetitive mild traumatic brain injury: a review. Journal of neurosurgery, 2013. 119 (5): p. 1235-1245.

[17] Post, A., Karton, C., Hoshizaki, T. B., and Gilchrist, M. D. Analysis of the protective capacity of ice hockey helmets in a concussion injury reconstruction. Proceedings of IRCOBI Conference, 2014.

[18] Hoshizaki, T. B., Walsh, E., et al. The application of brain tissue deformation values in assessing the safety performance of ice hockey helmets. Proceedings of the Institution of Mechanical Engineers, Part P: Journal of Sports Engineering and Technology, 2012. 226 (3-4): p. 226-236.

[19] Hoshizaki, T. B., Post, A., Oeur, R. A., and Brien, S. E. Current and future concepts in helmet and sports injury prevention. Neurosurgery, 2014. 75: p. S136-S148.

[20] King, A. I., Yang, K. H., Zhang, L., Hardy, W., and Viano, D. C. Is head injury caused by linear or angular acceleration. Proceedings of IRCOBI conference, 2003.

[21] Greenwald, R. M., Gwin, J. T., Chu, J. J., and Crisco, J. J. Head impact severity measures for evaluating mild traumatic brain injury risk exposure. Neurosurgery, 2008. 62 (4): p. 789.

[22] Gurdjian, E. S., Roberts, V., and Thomas, L. M. Tolerance curves of acceleration and intracranial pressure and protective index in experimental head injury. Journal of Trauma and Acute Care Surgery, 1966. 6 (5): p. 600-604.

[23] Versace, J. A review of the severity index. 1971, SAE Technical Paper.

[24] Giordano, C. and Kleiven, S. Evaluation of axonal strain as a predictor for mild traumatic brain injuries using finite element modeling. Stapp car crash journal, 2014. 58: p. 29.

[25] Takhounts, E. G., Craig, M. J., Moorhouse, K., McFadden, J., and Hasija, V. Development of brain injury criteria (BrIC). Stapp car crash journal, 2013. 57: p. 243.

[26] Clark, J. M., Post, A., Hoshizaki, T. B., and Gilchrist, M. D. Determining the relationship between linear and rotational acceleration and MPS for different magnitudes of classified brain injury risk in ice hockey. International Research Council on the Biomechanics of Injury (IRCOBI), Lyon (France), 2015.

[27] Holbourn, A. Mechanics of head injuries. The Lancet, 1943. 242 (6267): p. 438-441.

[28] Ommaya, A. and Hirsch, A. Tolerances for cerebral concussion from head impact and whiplash in primates. Journal of biomechanics, 1971. 4 (1): p. 13-21.

[29] Clark, J. M., Post, A., Hoshizaki, T. B., and Gilchrist, M. D. The Association among Injury Metrics for Different Events in Ice Hockey Goaltender Impacts.

[30] Post, A., De Grau, S., et al. Comparison of Helmeted Head Impact in Youth and Adult Ice Hockey.

[31] Ackery, A., Provvidenza, C., and Tutor, C. H. Concussion in hockey: compliance with return to play advice and follow-up status. Canadian Journal of Neurological Sciences/Journal Canadien des Sciences Neurologiques, 2009. 36 (02): p. 207-212.

[32] Benson, B. W., Meeuwisse, W. H., Rizos, J., Kang, J., and Burke, C. J. A prospective study of concussions among National Hockey League players during regular season games: the NHL-NHLPA Concussion Program. Canadian Medical Association Journal, 2011. 183 (8): p. 905-911.

[33] Goodman, D., Gaetz, M., and Meichenbaum, D. Concussions in hockey: there is cause for concern. Medicine and science in sports and exercise, 2001.33 (12): p. 2004-2009.

[34] Carlson, S. The Influence of Neck Stiffness, Impact Location, and Angle on Peak Linear Acceleration, Shear Force, and Energy Loading Measures of Hockey Helmet Impacts. 2016.

[35] Zerpa, C., Carlson, S., Elyasi, S., Przysucha, E., and Hoshizaki, T. Energy Dissipation Measures on a Hockey Helmet across Impact Locations. Journal of Safety Engineering, 2016. 5 (2): p. 27-35.

[36] Berti, S. Design of a Neck-Support-Incorporated Helmet for Reducing the Risk of Concussion in Ice Hockey. 2015, WORCESTER POLYTECHNIC INSTITUTE.

[37] Rousseau, P., Post, A., and Hoshizaki, T. The effects of impact management materials in ice hockey helmets on head injury criteria. Proceedings of the Institution of Mechanical Engineers, Part P: Journal of Sports Engineering and Technology, 2009. 223 (4): p. 159-165. 
[38] Halstead, P. D., Alexander, C. F., Cook, E. M., and Drew, R. C., "Safety in Ice Hockey: Third Volume", ASTM International, 2000.

[39] Spittle, E. K., Miller, D. J., Shipley Jr, B. W., and Kaleps, I. Hybrid II and hybrid III dummy neck properties for computer modeling. 1992, DTIC Document.

[40] Rivara, F. P., Astley, S. J., Clarren, S. K., Thompson, D. C., and Thompson, R. S. Fit of bicycle safety helmets and risk of head injuries in children. Injury Prevention, 1999. 5 (3): p. 194-197.

[41] Chang, L.-T., Chang, C. -H., and Chang, G. -L. Fit Effect of Motorcycle Helmet. JSME International Journal Series A Solid Mechanics and Material Engineering, 2001. 44 (1): p. 185-192.

[42] Yu, W. -Y., Chen, C. -Y., Chiu, W.-T., and Lin, M. -R. Effectiveness of different types of motorcycle helmets and effects of their improper use on head injuries. International journal of epidemiology, 2011: p. dyr040.

[43] Greenhill, D. A., Navo, P., et al. Inadequate Helmet Fit Increases Concussion Severity in American High School Football Players. Sports Health, 2016. 8 (3): p. 238-243.

[44] Hopes, P. and Chinn, B. Helmets: a new look at design and possible protection. Proceedings of INTERNATIONAL IRCOBI CONFERENCE ON THE, 1989.

[45] Gilchrist, A. and Mills, N. Impact deformation of ABS and GRP motorcycle helmet shells. Plastics rubber and composites processing and applications, 1994. 21 (3): p. 141-150.

[46] MacAlister, A. Surrogate Head Forms for the Evaluation of Head Injury Risk. Proceedings 2013.

[47] Coulson, N., Foreman, S., and Hoshizaki, T. Translational and rotational accelerations generated during reconstructed ice hockey impacts on a Hybrid III head form. Proceedings of Fifth International Symposium on Safety in Ice Hockey, 2009.

[48] McIntosh, A. S. and Janda, D. Evaluation of cricket helmet performance and comparison with baseball and ice hockey helmets. British journal of sports medicine, 2003. 37 (4): p. 325-330.

[49] Walsh, E. S., Rousseau, P., and Hoshizaki, T. B. The influence of impact location and angle on the dynamic impact response of a hybrid III headform. Sports Engineering, 2011. 13 (3): p. 135-143.

[50] Mihalik, J. P., Beard, J. R., Petschauer, M. A., Prentice, W. E., and Guskiewicz, K. M. Effect of ice hockey helmet fit on cervical spine motion during an emergency log roll procedure. Clinical Journal of Sport Medicine, 2008. 18 (5): p. 394-398.

[51] Petschauer, M. A. B., "Effectiveness of cervical spine stabilization during spine boarding of collegiate lacrosse athletes". 2006: University of North Carolina at Greensboro.

[52] Sherbondy, P. S., Hertel, J. N., and Sebastianelli, W. J. The effect of protective equipment on cervical spine alignment in collegiate lacrosse players. The American journal of sports medicine, 2006.34 (10): p. 1675-1679.
[53] Allen, E. B., "The effect of lacrosse helmet fit on cervical spine movement during a prone log roll". 2010: THE UNIVERSITY OF NORTH CAROLINA AT CHAPEL HILL.

[54] Daneshvar, D. H., Baugh, C. M., et al. Helmets and mouth guards: the role of personal equipment in preventing sport-related concussions. Clinics in sports medicine, 2011. 30 (1): p. 145-163.

[55] Forbes, J. A., Awad, A. J., Zuckerman, S., Carr, K., and Cheng, J. S. Association between biomechanical parameters and concussion in helmeted collisions in American football: a review of the literature. Neurosurgical focus, 2012. 33 (6): p. E10.

[56] Viano, D. C., Withnall, C., and Halstead, D. Impact performance of modern football helmets. Annals of biomedical engineering, 2012. 40 (1): p. 160-174.

[57] Rowson, S., Duma, S. M., et al. Can helmet design reduce the risk of concussion in football? Technical note. Journal of neurosurgery, 2014. 120 (4): p. 919-922.

[58] Jadischke, R. Football helmet fitment and its effect on helmet performance. 2012.

[59] Morehouse, C., "Safety in Ice Hockey", ASTM International, 1989.

[60] Emery, C. A. and Meeuwisse, W. H. Injury rates, risk factors, and mechanisms of injury in minor hockey. The American journal of sports medicine, 2006. 34 (12): p. 1960-1969.

[61] Zhang, L., Yang, K. H., and King, A. I. A proposed injury threshold for mild traumatic brain injury. Journal of biomechanical engineering, 2004. 126 (2): p. 226-236.

[62] Duma, S. M., Manoogian, S. J., et al. Analysis of real-time head accelerations in collegiate football players. Clinical Journal of Sport Medicine, 2005. 15 (1): p. 3-8.

[63] Willinger, R. m. and Baumgartner, D. Human head tolerance limits to specific injury mechanisms. International journal of Crashworthiness, 2003.8 (6): p. 605-617.

[64] Rousseau, P., Post, A., and Hoshizaki, T. A comparison of peak linear and angular headform accelerations using ice hockey helmets. Proceedings of Fifth International Symposium on Safety in Ice Hockey, 2009.

[65] Meaney, D. F. and Smith, D. H. Biomechanics of concussion. Clinics in sports medicine, 2011. 30 (1): p. 19-31.

[66] Zhang, L., Yang, K. H., and King, A. I. Comparison of brain responses between frontal and lateral impacts by finite element modeling. Journal of neurotrauma, 2001. 18 (1): p. 21-30.

[67] Sarvghad-Moghaddam, H., Karami, G., and Ziejewski, M. The effects of directionality of blunt impacts on mechanical response of the brain. Proceedings of ASME 2014 International Mechanical Engineering Congress and Exposition, Montreal, Canada, November 2014, 2014. Montreal, Canada.

[68] Kimpara, H. and Iwamoto, M. Mild traumatic brain injury predictors based on angular accelerations during impacts. Annals of biomedical engineering, 2012. 40 (1): p. 114-126. 